\title{
Gerakan 30 September: Narasi “Dewan Jenderal” Di Situs Berita Utama Indonesia Tahun 2017
}

\author{
Muhammad Aswan Zanynu \\ Jurusan Ilmu Komunikasi, Universitas Haluoleo, Kendari \\ azanynu@gmail.com
}

\begin{abstract}
The $30^{\text {th }}$ September Movement $(G 30 S)$ in 1965 is one of the important milestones of Indonesian political history. Historiography shows that the testimony of the G30S executor acknowledged that what they did was meant to precede the Council of Generals that plan to coup d'etat against President Soekarno. After more than five decades, it is important to know how new media (especially news website) pass on the memory of this Council of Generals especially for the new generation in Indonesia. The objective is to reveal, 1) the Council of Generals and the position of the Indonesia Communist Party or PKI in the G30S narration on the Indonesian news website, and 2) the argument used in the framing both the issues: Council of Generals and PKI. The study was conducted on three main news sites in Indonesia (Detik.com, Tribunnews.com, Liputan6.com) using framing analysis method to probe news from September to October 2017. This study found that the news about the Council of Generals was not presented in a way that meets the standard of rationality narrative as required by Walter Fisher's Narrative Paradigm theory. Nevertheless, the depiction of the Council of Generals and its members in the patriot/hero category was confirmed in the framing of the major Indonesian news sites. The PKI (still) remained positioned as a mastermind of G30S. Media does not provide any other version that can open the public's insight to better understand this incident. The tendency to report the moment of kidnapping and murder of the generals give emphasis more to the dramatic value than political aspect of the events. The media tend to present the Council of Generals and G30S as an issue of human interest rather than the significance of this tragedy in Indonesian history.
\end{abstract}

Keywords: Council of Generals, $30^{\text {th }}$ September movement, journalism, narrative

\begin{abstract}
ABSTRAK
Gerakan 30 September (G30S) 1965 merupakan salah satu tonggak penting sejarah politik Indonesia. Historiografi menunjukkan bahwa kesaksian eksekutor G30S mengakui bahwa apa yang mereka lakukan dimaksudkan untuk mendahului rencana Dewan Jenderal yang disinyalir akan melakukan kudeta kepada Presiden Soekarno. Setelah lebih dari lima dekade, menjadi penting untuk mengetahui cara media baru (khususnya situs berita) mewariskan memori terkait Dewan Jenderal ini kepada generasi baru di Indonesia. Tujuannya untuk mengungkap, 1) perihal Dewan Jenderal dan posisi Partai Komunis
\end{abstract}


Indonesia atau PKI dalam narasi G30S di situs berita Indonesia; dan 2) argumentasi yang digunakan dalam pembingkaian keduanya: Dewan Jenderal dan PKI. Penelitian dilakuan pada tiga situs berita utama di Indonesia (Detik.com, Tribunnews.com, Liputan6.com) dengan menggunakan metode analisis framing atas pemberitaan bulan September-Oktober 2017. Studi menemukan bahwa artikel Dewan Jenderal belum tersaji dengan cara yang memenuhi standar rasionalitas narasi sebagaimana disyaratkan teori Paradigma Naratif yang dikemukakan Walter Fisher. Meski demikian, penggambaran Dewan Jenderal dan anggotanya dalam kategori patriot/pahlawan, terkonfirmasi dalam pembingkaian yang dilakukan situs berita utama Indonesia. Dalam konteks G30S, PKI tetap diposisikan sebagai dalang. Media tidak memberikan versi lain yang dapat membuka wawasan publik untuk memahami lebih baik tentang peristiwa ini. Kecenderungan untuk menyajikan momen penculikan dan pembunuhan, menggiring pembingkaian lebih pada aspek dramatis ketimbang politis yang melatarbelakangi keseluruhan peristiwa. Media tampak ingin menghadirkan Dewan Jenderal dan G30S sebagai sebuah isu dan peristiwa yang menonjolkan nilai human interest ketimbang nilai penting peristiwa tersebut dalam sejarah Indonesia.

\section{Kata kunci: Dewan Jenderal, G30S, jurnalisme, narasi}

\section{PENDAHULUAN}

Ada dua pendulum kekuasaan yang berpengaruh di awal era 1960-an: Angkatan Darat (AD) dan Partai Komunis Indonesia (PKI). Presiden Soekarno saat itu tampil sebagai penengah dua kekuatan ini. Era yang dikenal dengan nama Demokrasi Terpimpin ini (1959-1966) ditandai dengan berpusatnya seluruh keputusan politik di tangan Presiden Soekarno. Selain sebagai Kepala Negara Republik Indonesia, Soekarno juga dikenal sebagai Pemimpin Besar Revolusi Indonesia yang sejak 1963 diangkat sebagai Presiden Seumur Hidup. Meski ingin menjadi penengah, dalam praktiknya Soekarno lebih berpihak kepada PKI. Berlaki-kali ia menyebutkan bahwa revolusi Indonesia adalah Revolusi Kiri.

Pada bulan Agustus 1960 ia membubarkan Partai Masyumi (Partai
Majelis Syuro Muslimin Indonesia) yang merupakan partai terbesar kedua di Indonesai —dan Partai Islam terbesar pertama - dalam Pemilu 1955. Masyumi dituduh mendukung pemberontakan PRRI (Pemerintahan Revolusioner Republik Indonesia) di Sumater Barat. Selain Masyumi, Soekarno juga membubarkan Partai Sosialis Indonesia (PSI) dengan tuduhan bergabung dengan pemberontakan PRRI. Pemimpin Masyumi dan PSI kemudian dipenjarakan (Wanandi, 2014: 17). Kebijakan yang diambilnya ini, dilihat sebagai hasil manuver politik PKI. Sama halnya dengan pembubaran Partai Murba (Musyawarah Rakyat Banyak).

$$
\text { Partai Murba - termasuk }
$$

organisasi massa dan lembaga lain yang berinduk dan bernaung pada partai inidibubarkan pada tanggal 6 Januari 1965. Partai Murba terkenal kerap tidak sejalan 
dengan PKI dan selalu menentang aksi penyerobotan lahan milik warga atau swasta yang dilakukan Barisan Tani Indonesia (BTI) yang mengatasnamakan Reformasi Agraria. Partai Murba menilai, aksi-aksi sepihak tersebut membawa kehancuran total bagi persatuan nasional yang sangat diperlukan dalam perjuangan menentang neokolonialisme dan imperialisme (Hadi, 2017: 129). Argumentasi ini tidak meluluhkan Soekarno untuk mengeluarkan pelarangan tersebut.

Saat perayaan hari ulang tahun PKI yang ke-45 pada tanggal 23 Mei 1965, Soekarno (kembali) menegaskan dukungannya kepada PKI, partai ini ia nilai merupakan pengejawantahan Marxisme yang sebenarnya. Tidak seperti PSI yang disebutnya sebagai pencoleng Marxisme. Di kesempatan tersebut, Soekarno menjelaskan alasan mengapa ia menggunakan istilah Nasakom (Nasionalis, Agama, Komunis). Dalam pidatonya, Soekarno berkata: “... saya dengan sengaja memakai perkataan Kom, Nasakom, karena di Indonesia banyak orang yang ... phobia kepada Kom ... khususnya takut kepada PKI, benci kepada PKI, hendak menghancurleburkan PKI. Terus terang saja ... di kalangan Nas ada yang Komonisto phobia, di kalangan Agama ada yang Komonisto phobia, di kalangan Angkatan Bersenjata dulu ada yang ber-Komonisto phobia. Nah, ini penyakit phobia ini hendak saya brantas saudara-saudara, hendak saya brantas" (Soekarno, 1965: 12-13).
Mengapa dalam pidato tersebut Soekarno juga menyebut Angkatan Bersenjata? Padahal Nasakom hanya berkaitan dengan ideologi di luar militer yang ingin disatukan oleh Soekarno? Sedikitnya ada dua penjelasan untuk itu. Pertama, Jenderal Ahmad Yani pada suatu kesempatan pernah mengajukan ide untuk mengganti Nasakom menjadi Nasasos (Nasionalis, Agama, Sosialis) agar lebih banyak yang terakomodasi dalam kata 'sosialis' (Sos) tersebut. Jika banyak pihak yang dapat bergabung dengan kaum nasionalis dan kaum pula agama, dengan Nasakom, praktis hanya PKI yang terwakili yakni dalam unsur Kom. Lebih kurang begitu penjelasannya. Namun ide ini ditolak oleh Presiden Soekarno (Hadi, 2017: 183). Kedua, Soekarno sudah mencurigai adanya indikasi apa yang ia sebut sebagai "Komonisto phobia" dalam tubuh Angkatan Bersenjata. Sebagaimana dikemukakan pada bagian awal tadi, ada tiga poros kekuasaan yang saling tarikmenarik di awal 1960-an, dan Angkatan Bersenjata tidak sepenuhnya bebas dari tarik menarik tiga poros kekuatan ini. Dalam pidatonya, Soekarno seolah membidik kelompok komonisto phobia di tubuh Angkatan Bersenjata yang sedang berkonsolidasi.

Ada dari kekuatan Angkatan Bersenjata (Angkatan Laut, Udara, serta Kepolisian) yang menjadi loyalis Soekarno, ada yang bersimpati dan menjadi pendukung PKI, dan ada pula yang memilih untuk bergabung dengan $\mathrm{AD}$ yang antikomunis. Di tubuh $\mathrm{AD}$ 
sendiri tidak sepenuhnya antikomunis. Sedikitnya ada empat faksi jika dilihat dari posisi mereka atas PKI. Pertama, yang antikomunis dan menunjukkan permusuhannya kepada PKI. Faksi ini dipimpin oleh Nasution. Kedua, faksi Yani yang meski antikomunis tetapi lebih memilih jalan diplomatis saat berhadapan dengan PKI. Ketiga, faksi Soeharto yang tidak menunjukkan dengan tegas sikap antikomunis mereka kepada PKI. Mereka lebih terlihat sebagai kelompok yang 'netral'. Keempat, adalah faksi yang menjadi binaan PKI. Bagi PKI dan kelompok yang keempat di tubuh AD ini, faksi Nasution dan Yani yang dianggap berbahaya. Sementara Soeharto dan kawan-kawannya dilihat sebagai faksi yang (sangat mungkin) akan memilih sikap apolitis atau malah mendukung komunis.

Ketika isu Dewan Jenderal muncul dalam rapat yang dipimpin Soekarno pada tanggal 26 Mei 1965, Ahmad Yani diminta untuk memberi klarifikasi. Menurutnya tidak ada Dewan Jenderal di tubuh AD, yang ada hanyalah Wanjakti (Dewan Jabatan dan Kepangkatan Perwira Tinggi) yang memberi rekomendasi tentang kenaikan pangkat para perwira senior (Hadi, 2017: 163), namun penjelasan tersebut tidak memuaskan. Menurut Dake (2005: 261264), Soekarno justru mencurigai bahwa Wanjakti ini yang dipersiapkan sebagai satu awal dibentuknya Dewan Jenderal. Wanjakti itu sendiri adalah hasil dari pertemuan tanggal 13 Januari 1965 yang dihadiri sejumlah jenderal AD. Dalam pertemuan ini, Nasution maupun Yani tidak hadir. Historiografi menunjukkan bahwa kesaksian aktor lapangan Gerakan 30 September (G30S) tahun 1965 mengakui bahwa apa yang mereka lakukan dimaksudkan untuk mendahului rencana Dewan Jenderal yang disinyalir akan melakukan kudeta kepada Presiden Soekarno. Rencana aksi pre-emptive itu disampaikan DN Aidit kepada Kepala Biro Khusus PKI Syam Kamaruzaman pada 12 Agustus 1965 (Fic, 2008: 119).

Pasca-1965, narasi PKI dan G30S bertahan selama tiga dekade di Indonesia. Padahal masih ada sedikitnya empat skenario yang menjelaskan skenario lain dibalik gerakan ini: 1) G30S sebagai masalah internal AD; 2) Soekarno yang bertanggung jawab atas G30S; 3) Soeharto dibalik G30S; dan 4) perang jaringan intelijen dan CIA (Sulistyo, 2011: 56-67). Setelah Presiden Soeharto mengundurkan diri pada 21 Mei 1998, narasi yang menghubungkan PKI dengan aksi G30S kurang mendapat titik tekan lagi. Film berjudul Pengkhianatan G30S/PKI yang diproduksi tahun 1984, tidak lagi wajib ditayangkan oleh stasiun televisi sejak tahun itu (1998). Buku-buku sejarah perlahan tidak menggandengkan G30S dengan PKI. Narasi tentang keterlibatan PKI pun dipertanyakan kembali dalam aksi peristiwa G30S. Di bulan Mei 2016 menyeruak isu kebangkitan komunis, pro-kontra terjadi di ruang publik. Ada yang percaya, ada pula yang menilai bahwa itu adalah ketakutan yang berlebihan. Namun rasa ingin tahun publik atas isu ini tidak 
kunjung surut. Google Trends menunjukkan bahwa sejak G30S berusia setengah abad (September 2015) sampai Februari 2018, bulan September 2017 adalah waktu di mana berita tentang topik G30S menduduki puncak perhatian publik di ranah maya.

\section{Internet dipercaya memiliki} penetrasi informasi relatif lebih luas, murah, serta praktis dibandingkan dengan media cetak, radio, atau televisi. Dalam kondisi seperti ini, situs berita menjadi pilihan untuk memperbaharui setiap informasi yang terjadi. Situs mudah diakses dari berbagai piranti, terkhusus piranti bergarak (gadget) karena mendukung segala platform pesan: teks, foto, audio, bahkan audio visual. Meski tidak selengkap media cetak seperti suratkabar atau majalah, situs berita dapat menambahkan sejumlah tautan (link) yang memungkinkan untuk melacak ke latar sebuah berita (background news) yang terlewatkan atau bagian lain yang dianggap memiliki relevansi dengan apa yang menjadi topik berita. Sistem pengarsipan yang serba digital dan mudah diakses ini memberi keleluasaan publik untuk mengoptimalkan pencariannya, memuaskan kebutuhan informasinya. Satu hal lagi yang tak dapat dipungkiri, generasi baru Indonesia cenderung menggunakan internet daripada media konvensional. Data Indonesia Digital Landscape 2018 menunjukkan bahwa penetrasi internet telah mencapai 74,23 persen pada kelompok usia 19-33 tahun di Indonesia.

\section{Grafik 1.}

Kecenderungan Minat atas Berita G30S

(Agustus 2015 sampai Februari 2018)

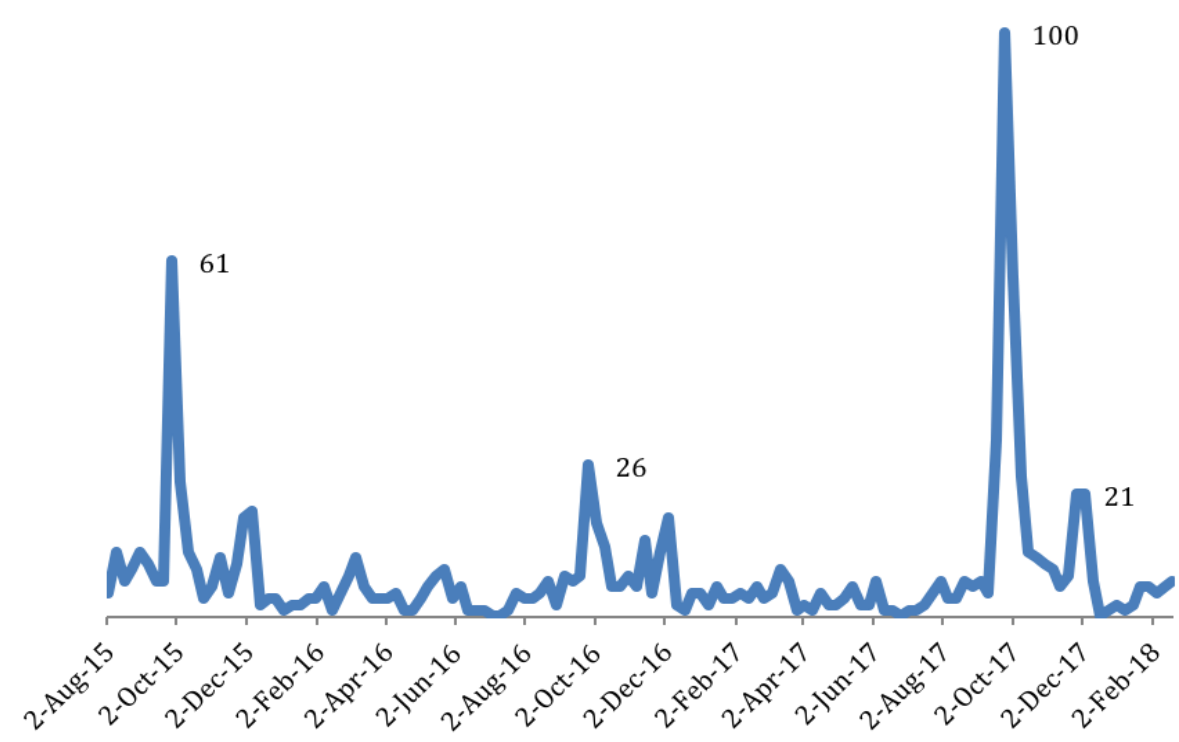

Sumber: Google Trends 2018 
Setelah melewati lima dekade sejak 1965 dan dua dekade setelah turunnya Soeharto di tahun 1998, menjadi penting untuk mengetahu cara media massa khususnya situs berita mewariskan memori atas peristiwa tersebut. Bagaimana situs berita utama di Indonesia menyajikan narasi Dewan Jenderal dalam peristiwa G30S? Pertanyaan ini diajukan untuk mengungkap: 1) perihal Dewan Jenderal dan posisi PKI dalam narasi G30S di situs berita Indonesia; dan 2) argumentasi yang digunakan dalam pembingkaian keduanya.

\section{KERANGKA PEMIKIRAN}

Walter Fisher (dalam Griffin, 2012: 312) mendefinisikan narasi sebagai tindakan simbolik berupa kata dan/atau tindakan yang memiliki rangkaian dan makna bagi mereka yang menyampaikan, menciptakan, atau menginterpretasikannya. Ada lima asumsi dasar teori Paradigma Naratif ini. Pertama, manusia pada dasarnya dipandang sebagai penutur kisah. Komunikasi dipandang sebagai fenomena penuturan kisah yang tidak tunggal atau berdiri sendiri. Sebelumnya sudah ada pengetahuan awal yang mendasarinya dan dari situ kisah dipahami secara bersama dan dikembangkan. Asumsi kedua, keputusan yang kita dalam berkomunikasi -baik itu saat memproduksi atau memproses pesan - dibuat berdasarkan pada apa yang disebut sebagai "pertimbangan yang baik" (Fisher menyebutnya dengan istilah good reasons). Pertimbangan ini yang bergantung pada situasi komunikasi, media dan genre filosofis, teknis, retoris, atau artistik.

Asumsi ketiga teori Paradigma Naratif menyebutkan bahwa sejarah, biografi, budaya, dan karakter ditentukan oleh apa yang kita pahami sebagai "pertimbangan yang baik". Dengan kata lain, sejarah, biografi, budaya, dan karakter itu dibangun atas pemahaman kita tentang argumentasi-argumentasi yang dapat terpercaya. Keempat, untuk mencapai tingkat kredibilitas sebuah narasi, rasionalitas naratif yang terdiri dari koherensi dan ketepatan kisah yang menjadi indikasinya. Pada akhirnya teori ini melihat bahwa manusia hidup di dunia yang mereka pahami dari seperangkat kisah yang pilihan dan terus-menerus membentuk kembali kehidupannya.

Teori Paradigma Naratif ini merupakan bagian dari tradisi sosialbudaya yang mendasarkan premisnya pada bahasa sebagai piranti yang digunakan manusia untuk membentuk dunia. Ketika manusia berkomunikasi, saat itu mereka juga memproduksi dan mereproduksi budaya. Merujuk pada hipotesis Sapir-Whorf, bahasa pada dasarnya adalah penyusun persepsi manusia atas realitas. Dengan bahasa, realitas diproduksi, dipertahankan, diperbaiki, dan ditransformasikan (Griffin, 2012: 43). Meski sekilas memiliki irisan dengan konstruksi sosial, Griffin (2012: 473-486) tidak 
memasukkannya dalam akar teori konstruksi sosial. Dari sepuluh akar teori yang ia kemukakan, Paradigma Naratif dikelompokkan ke dalam akar naratif dengan bertimbangan bahwa kisah (story) sebagai kata atau perbuatan yang memiliki kesinambungan makna, dilihat sebagai sesuatu yang terus hidup, tercipta, dan diinterpretasikan.

Merujuk pada asumsi ketiga tadi, G30S sebagai sebuah peristiwa sejarah yang dituturkan kembali dan terus menerus oleh media, dapat didekati dengan teori Paradigma Naratif. Esensi dari narasi itu sendiri terletak pada dua hal: "koherensi" dan "ketepatan". Menurut Fisher (1987: 47), koherensi disusun oleh kesesuaian struktur argumentasi, substansi atau materi pesan, dan kategori karakter yang dapat disimpulkan melalui seperangkat kecenderungan yang termuat dalam narasi. Sementara ketepatan menurut Griffin (2012: 314) ditandai dengan dengan adanya relevansi antara substansi pesan dengan apa yang dinilai sebagai sebuah kebenaran. Dengan kata lain, koherensi adalah kesesuaian substansi narasi yang ditemukan dalam relasi intrateks. Sementara ketepatan adalah kebenaran narasi yang terkonfirmasi dari konfirmasi antarteks.

Narasi berita sebagai hasil dari tindakan simbolik jurnalis memiliki relevansi dengan asumsi-asumsi Fisher ini. Jurnalis pada dasarnya adalah seorang penutur kisah. Agar argumentatif, berita yang mereka buat sedapat mungkin dikemas agar dapat memenuhi kriteria rasionalitas naratif tadi. Hal ini penting karena berita — sebagaimana layaknya pesan komunikasi yang lain - akan digunakan untuk pengambilan keputusan.

Menurut Bell dan Garrett (dalam Fulton et al. 2005: 227-228), jurnalis pada dasarnya tidak membuat tulisan, mereka menulis kisah dengan struktur, urutan, sudut pandang dan nilai-nilai tertentu. Darnton (dalam McQuail, 2010: 383) berpendapat bahwa berita dihasilkan melalui cara lama menuturkan kisah. Laporan berita biasanya ditampilkan dalam bentuk narasi dengan aktor utama dan sampingan, urut-urutan yang saling berhubungan, pahlawan dan penjahat, babakan awal-tengah-akhir. Itu semua menandakan kejadian dramatis dan bersandar pada alur cerita yang akrab dengan audiens.

Bagi Bird dan Dardenne (dalam McQuail, 2010: 383), berita sebagai narasi membantu untuk memaknai pelaporan pengalaman jurnalis. Baik itu dalam bentuk 1) menghubungkan tindakan dan peristiwa dalam cara yang logis, berurutan serta timbal balik, atau 2) dengan menyediakan elemen orang dan tempat yang memiliki karakter tetap dan dapat dipahami karena realistis. Naratif membantu memberikan logika dari motif manusia yang memaknai pengalaman tersebut secara terpisah.

\section{METODE PENELITIAN}

Untuk mengungkap cara situs berita utama di Indonesia menyajikan narasi Dewan Jenderal dalam peristiwa G30S (termasuk memposisikan PKI, serta 
dan para tokoh yang terkait G30S), penelitian ini menggunakan metode analisis framing dengan model yang ditawarkan oleh Murray Edelman. Menurut Edelman, apa yang kita ketahui tentang realitas atau tentang dunia tergantung pada bagaimana kita membingkainya dan mengkonstruksi atau menafsirkan realitas. Realitas yang sama bisa jadi akan berbeda jika dibingkai atau dikonstruksi dengan cara yang berbeda (Eriyanto, 2011: 155). Edelman menggunakan kata "kategori" untuk menjelaskan apa yang dia maksud sebagai pembingkaian.

Model yang ditawarkan Edelman ini memiliki relevansi dengan perspektif yang digunakan dalam berkisah (sudut pandang "kita" dan "mereka"), serta elemen koherensi dan ketepatan yang ingin diungkap dari narasi. Pendekatan kategori yang dia ajukan membantu untuk mengidentifikasi cara narasi Dewan Jenderal disajikan kembali. Kategori adalah cara yang digunakan media untuk menyederhanakan realitas yang kompleks dan tidak beraturan. Di satu sisi, ini membantu kita untuk mengurai begitu banyak hal, namun di sisi lain kategori ini tanpa disadari menggiring kita untuk melihat sebuah isu atau peristiwa dengan sudut pandang yang diinginkan oleh media. Selain itu, karena bentuknya adalah penyederhanaan, maka ada bagianbagian tertentu yang tidak disampaikan. Kategori, secara langsung dapat dilihat pada rubrikasi berita dan judul yang digunakan. Bahasa, khususnya pilihan kata (diksi), menjadi alat yang digunakan untuk membentuk kategori. Sekawanan pasukan bersenjata yang melakukan aksinya dapat digambarkan sebagai "pejuang" atau "pemberontak", tergantung ke kategori mana media membingkai atau menuturkan peristiwa tersebut.

Pendekatan model kategori dari Edelman dapat digunakan untuk melihat cara Dewan Jenderal, peristiwa G30S, dan PKI dikonstruksi kembali oleh media. Dari cara media melakukan kategorisasi ini dapat menentukan siapa yang disebut oleh media sebagai "pihak kita" dan "pihak mereka", serta argumentasi yang dipilih untuk mendukung ketagori yang mereka buat. Di bagian terakhir ini (argumentasi) akan diungkap rasionalitas narasi yang digunakan oleh media, terpenuhi atau tidak elemen koherensi dan ketepatan yang disyaratkan oleh Fisher sebagaimana yang dikemukakan dalam teori Paradigma Naratif.

Dengan banyaknya situs berita di Indonesia, penelitian ini mengkhususkan diri pada situs berita yang menduduki peringkat tiga besar yang paling sering dikunjungi pada tahun 2017. Web yang mengkhususkan diri pada analisis lalu lintas data internet Alexa.com, merilis tiga situs berita yang paling sering dikunjungi di Indonesia yaitu: Detik.com, Tribunnews.com, dan Liputan6.com. Berita yang dipilih adalah yang menjadikan tokoh di sekitar G30S sebagai judul atau topik ulasan dan terpublikasi pada bulan September hingga Oktober 2017 di tiga situs tersebut. Setiap berita dianalisis kategori, koherensi 
intrateks, dan ketepatan antarteks. Khusus untuk ketepatan, analisis antarteks dilakukan dengan manjadikan berita di situs lain (di luar tiga situs utama) sebagai pembanding.

\section{HASIL DAN PEMBAHASAN}

Secara umum, para jenderal yang menjadi korban G30S digambarkan sebagai sosok pahlawan. Situs berita Detik.com menurunkan lima artikel, masing-masing tentang Ahmad Yani, DI Pandjaitan, MT Haryono, Soeprapto, dan Parman. Yani digambarkan sebagai jenderal berprestasi yang penah menerima sedikitnya sembilan Bintang Kehormatan, di antaranya Bintang Sakti dan Bintang Gerilya (Dariyanto, 2017d). Religiusitas DI Pandjaitan ditampilkan dalam berita yang menggambarkan dia masih dalam posisi berdoa saat sebutir peluru ditembakkan ke bagian kepalanya oleh prajurit Cakrabirawa yang mengaku diutus Sukarno (Dariyanto, 2017c). MT Haryono juga roboh ditembak dari belakang saat dia mencoba merebut senjata dari "gerombolan Cakrabirawa" (Dariyanto \& Wildansyah, 2017).

Meski pelaku penculikan adalah resimen Cakrabirawa, situs berita Detik.com menyebut bahwa pembunuhan itu dilakukan oleh PKI:

Mayjen
Soeprapto ....
dibawa oleh
prajurit
Tjakrabirawa
ke Lubang
Buaya di
kawasan

Halim, Jakarta
Timur. Di
tempat itu
Mayjen
Soeprapto
bersama lima
jenderal dan
satu perwira
TNI $\quad \mathrm{AD}$
dibunuh oleh
gerombolan
Partai

Komunis

Indonesia.

Jenazah

mereka

kemudian

dimasukkan ke

sebuah sumur

tua di Lubang

Buaya dan

baru

ditemukan tiga hari kemudian.

(Dariyanto, 2017a)

Demikian pula ketika mengisahkan firasat yang ditunjukkan S. Parman. Setengah tahun sebelum peristiwa yang merenggut nyawanya, Parman berjalan-jalan dengan sang istri di Taman Makam Pahlawan, Kalibata. Persis di depan gerbangnya, ia mendadak menghentikan mobilnya. Kepada sang istri, ia berpesan agar setelah meninggal nanti dimakamkan di TMP Kalibata. Parman merasa itu adalah tempat istirahat abadinya yang membahagiakan. Dia juga berpesan agar di batu nisannya nanti dibuat tulisan: Pejuang Sejati (Dariyanto, 2017b). Dalam pemberitaannya, Detik.com menyematkan PKI berdekatan dengan G30S (G30S/PKI). 
Tidak ada ulasan langsung yang menghubungkan para korban G30S dengan Dewan Jenderal yang dapat ditemukan dalam Detik.com. Kisah Dewan Jenderal mucul dalam artikel Tribunnews.com. Disebutkan bahwa dalam sebuah kursus perwira di Bandung, Brigjen Ahmad Soekendro mengakui keberadaan Dewan Jenderal. Namun tidak seperti yang dituduhkan akan melakukan kudeta. Menurutnya, kelompok ini justtru aktif melakukan counter politik untuk menandingi dominasi PKI. Anggotanya 25 orang, namun empat penggeraknya adalah Mayjen S Parman, Mayjen MT Haryono, Brigjen Sutoyo Siswomihardjo, dan Brigjen Sukendro sendiri (Surono, 2017). Ditilik dari nama-nama tersebut, memang benar bahwa keempat tokoh penting Dewan Jenderal ini masuk dalam daftar penculikan G30S — selain Jenderal AH Nasution, Letnan Jenderal Ahmad Yani, Mayjen R. Soeprapto, Brigjen Donald Izacus Pandjaitan. Brigjen Ahmad Soekendro lolos dari penculikan karena karena diminta oleh Presiden Soekarno untuk menjadi anggota delegasi Indonesia untuk peringatan Hari Kelahiran Republik Cina, 1 Oktober 1965.

Saat Nasution menjadi Kepala Staf Angkatan Darat (KSAD), dia memilih Sukendro sebagai Asintel I KSAD. Seiring dengan tugas belajar yang diperolehnya di Amerika Serikat (AS), ia juga sukses menjalin kontak dengan CIA. Beberapa program kerjasama TNI dan CIA, diperoleh melewati tangannya. Sampai-sampai ada anggapan pada masa itu, sosok Sukendro-lah temali utama yang menghubung Nasution dan juga Achmad Yani dengan CIA. Menurut Surono (2017), dalam salah satu versi skenario Gestok, karena kecerdasan dan lobi baiknya dengan CIA, Sukendro disebut-sebut sebagai salah satu orang yang layak dicurigai sebagai dalang, seperti disebut dalam buku Menguak Misteri Kekuasaan Soeharto karangan FX Baskara Tulus Wardaya. Jika di satu sisi dianggap sebagai dalang, sisi lain apa yang membuat Sukendro masuk dalam daftar bidikan PKI? Sukendro termasuk sosok penting di tubuh militer. Namanya masuk dalam grup jenderal elite yang dekat dengan Nasution maupun Ahmad Yani.

Berbeda dengan apa yang dikemukakan oleh Sukendro, oleh para pelaku penculikan dari satuan Cakrabirawa, Dewan Jenderal digambarkan sebagai elit tentara yang hidup dalam kemewahan, "jam dinding di rumahnya saja terbuat dari emas". Sementara mereka (para pelaku penculikan) hanyalah prajurit bawahan, "Beli kaus singlet pun kita sudah tidak bisa". Seorang anggota Cakrabirawa menyebut Dewan Jenderal sebagai kelompok yang "akan membunuh Presiden pada tanggal 5 Oktober" dan tugas Cakrabirawa adalah mengawal dan menjaga Presiden. Mereka mengklain bahwa aksi G30S bertujuan untuk menyelamatkan Presiden Soekarno (Wardayati, 2017). Meski sepanjang artikel ini tidak ada argumentasi yang mendukung pernyataan bahwa Dewan Jenderal akan membunuh Soekarno, 
namun saat dilakukan pemeriksaan ulang antarteks, dapat ditemukan pernyataan bahwa Dewan Jenderal akan melakukan kudeta.

Artikel yang berjudul Pengakuan Eks Cakrabirawa yang Menjemput Para Jenderal, Latif dan Untung Lapor ke Soeharto, juga memuat dugaan dari anggota Cakrabirawa bahwa Dewan Jenderal akan melakukan kup. Seorang narasumber, Sulemi (eks Cakrabirawa) yang saat itu mendapatkan perintah untuk menjemput Jenderal AH Nasution, mengemukakan:

... memang betul pada waktu itu ada informasi [tanggal 5 Oktober] akan ada kup dari Dewan Jenderal ke pimpinan besar revolusi Bung Karno, sehingga perlu diadakan pencegahan. Jadi kami selaku prajurit diperintahkan oleh atasan, doktrinnya tidak ada seorang prajurit yang diperintahkan atasannya bilang tidak mau. Semua perintah atasannya harus dilaksanakan, [termasuk] untuk mengambil Dewan Jenderal agar supaya menghadap ke Bung Karno ke istana. (Prasetiyo, 2017)

Menurutnya, Nasution membangkang karena tidak patuh pada panggilan Presiden dan malah melarikan diri. Sulemi membantah pasukan
Cakrabirawa sengaja menembak anak Nasution. Saat itu, senjata dibidikkan ke pintu yang dikunci. Hingga akhir artikel, tidak ada argumentasi atau data yang mempertegas rencana kup Dewan Jenderal sebagaimana diklaim Sulemi.

Terdapat satu artikel lagi yang menampilkan versi narasi lain tentang Dewan Jenderal yang bertajuk Militer AS Sudah Siap Menginvasi Indonesia Jika Upaya CIA Mendorong G30S Urung Terjadi. Artikel ini menyebutkan bahwa Dewan Jenderal adalah buatan AS melalui agen intelijen mereka (CIA). Dewan ini sebenarnya tidak ada, tetapi dibuat sedemikian rupa agar tampak seperti ada: “... isu Dewan Jenderal yang sebenarnya dihembuskan oleh CIA melalui tokoh-tokoh militer dan PKI yang berhasil direkrut, memunculkan reaksi berupa G30S yang mengakibatkan gugurnya tujuh Pahlawan Revolusi" (Winardi, 2017). Hal ini merupakan rangkaian dari upaya CIA untuk menggulingkan Presiden Soekarno yang dinilai terlalu condong pada komunisme. Sama halnya dengan artikel lain yang menyinggung Dewan Jenderal, penelusuran intrateks tidak menunjukkan adanya koherensi dari informasi ini. 
Matriks 1.

Bingkai Kategori Artikel tentang Dewan Jenderal dan

Peristiwa G30S di Situs Berita Utama Indonesia

(September - Oktober 2017)

\begin{tabular}{|c|c|c|}
\hline \multirow{2}{*}{ TEMA } & \multicolumn{2}{|c|}{ KETEGORI } \\
\hline & KITA & MEREKA \\
\hline Dewan Jenderal & $\begin{array}{l}\text { - } \text { counter politik lawan PKI } \\
\text { - pahlawan } \\
\text { - religius } \\
\text { - korban }\end{array}$ & $\begin{array}{l}\text { - akan membunuh Presiden } \\
\text { - akan melakukan kup } \\
\text { - melawan Presiden } \\
\text { - gaya hidup mewah }\end{array}$ \\
\hline G30S & $\begin{array}{l}\text { - PKI sebagai dalang } \\
\text { - PKI kejam } \\
\text { - Cakrabirawa itu gerombolan }\end{array}$ & $\begin{array}{l}\text { - PKI sebagai penyelamat } \\
\text { - PKI bertindak antisipatif } \\
\text { - Cakrabirawa prajurit patuh }\end{array}$ \\
\hline
\end{tabular}

Sumber: Data Primer (2017)

Dari nukilan beberapa artikel yang terjadi di atas menunjukkan bahwa Dewan Jenderal disajikan oleh media dengan menggunakan perspektif "kita" dan "mereka". Saat memposisikan pembingkaian sebagai "mereka", sebagaimana terlihat pada Matriks 1, Dewan Jenderal adalah kelompok pembangkang, secara terang-terangan menentang bahkan berencana menggulingkan Presiden Soekarno. Sementara dengan perspektif "kita", Dewan Jenderal dilihat sebagai sebuah kelompok patriot yang sedang berhadapan dengan kekuatan komunis (dalam hal ini PKI). Sebuah drama melibatkan dua bersaudara berbeda ideologi tersaji dalam artikel berjudul Kisah Letjen S Parman, Korban G30S yang Adik Tokoh PKI.

Jabatan resmi Parman ketika G30S terjadi adalah Asisten I/Intelijen Menpangad A Yani. Dia digambarkan sebagai tokoh yang mencintai kokohnya persatuan Indonesia karena menolak pembentukan Angkatan Kelima. Dia menganggap keberadaan Angkatan Kelima malah memicu perang saudara. Berbeda dengan sang kakak, Ir. Sakirman yang merupakan anggota di Politbiro PKI. Sebagai salah satu elite di PKI, Sakirman berjuang keras dan berupaya meyakinkan Presiden Sukarno agar segera dibentuk Angkatan kelima yang terdiri dari kaum Buruh dan Tani yang dipersenjatai. Sakirman sendiri bukan orang asing bagi Soekarno. Mengutip karya Soe Hok Gie, Orang-Orang di Persimpangan Kiri Jalan, jurnalis Liputan6.com Rimadi (2017) menulis bahwa Sakirman bersama DN Aidit, Lukman, dan Sidik Kertapati sempat bergabung dalam Barisan Pelopor Istimewa, semacam pengawal pribadi Bung Karno pada masa pendudukan Jepang.

Meskipun menampilkan fakta bahwa Sakirman itu juga adalah pejuang 
di masa Jepang, artikel ini tetap memenjadikan Parman sebagai 'pahlawan'. Padahal di masa pendudukan Jepang, Parman pernah bekerja sebagai penerjemah pemerintah Jepang. Artikel ini memperkuat argumentasinya bahwa Parman memiliki rasa nasionalisme yang lebih tinggi (daripada sang kakak) dengan menyebutkan bahwa meski membantu Jepang, Parman disebut memiliki rasa nasionalisme yang tetap tinggi dengan terus berhubungan dengan temantemannya yang berjuang melalui gerakan bawah tanah. Fakta lain (yang tidak dapat ditandingi oleh sang kakak) adalah Parman ikut bergerilya dalam melawan Agresi Militer Belanda II.

Seperti yang telah diungkap pada bagian awal, tidak semua narasi tentang Dewan Jenderal ini dapat terkonfirmasi secara internal untuk menilai koherensi naratifnya. Seperti yang tampak dalam Matriks 2, hanya ada tiga kategori yang memenuhi kriteria Rasionalitas Naratif dari Fisher yakni 1) Dewan Jenderal adalah pahlawan, 2) PKI sebagai dalang G30S, dan 3) resimen Cakrabirawa adalah pasukan yang menjadi eksekutor penculikan. Tidak ada satu pun artikel yang secara khusus mengulas Dewan Jenderal. Topik ini terselip di sejumlah artikel. Tampak bahwa isu ini tidak terlalu menarik untuk ditampilkan kembali. Media lebih menyukai aspek dramatis sebuah kisah daripada mengkhususkan diri mengulas sebuah topik yang sebenarnya jadi pemantik sebuah perubahan besar yang terjadi dalam sejarah Indonesia.

Matriks 2.

Rasionalitas Naratif dalam Artikel tentang Dewan Jenderal dan Peristiwa G30S di Situs Berita Utama Indonesia (September - Oktober 2017)

\begin{tabular}{|c|c|c|}
\hline \multirow{2}{*}{ TEMA } & \multicolumn{2}{|c|}{ RASIONALITAS NARASI } \\
\hline & KOHERENSI & KETEPATAN \\
\hline Dewan Jenderal & $\begin{array}{l}\text { - akan membunuh Presiden (-) } \\
\text { - akan melakukan kup (-) } \\
\text { - counter politik lawan PKI (-) } \\
\text { - buatan CIA (-) } \\
\text { - pahlawan (+) }\end{array}$ & $\begin{array}{l}\text { - akan membunuh Presiden (-) } \\
\text { - akan melakukan kup (+) } \\
\text { - counter politik lawan PKI (-) } \\
\text { - buatan CIA (-) } \\
\text { - pahlawan (+) }\end{array}$ \\
\hline G30S & $\begin{array}{l}\text { - PKI sebagai dalang }(+) \\
\text { - Cakrabirawa sebagai eksekutor }(+)\end{array}$ & $\begin{array}{l}\text { - PKI sebagai dalang }(+) \\
\text { - Cakrabirawa sebagai eksekutor }(+)\end{array}$ \\
\hline
\end{tabular}

Sumber: Data Primer (2017)

Keterangan:

$+=$ terkonfirmasi

$-=$ tidak terkonfirmasi 
Salah satu artikel yang sama sekali tidak menunjukkan indikasi sebuah narasi yang baik adalah yang menyebutkan bahwa Dewan Jenderal adalah buatan CIA. Jika menelisik keseluruhan narasi yang tergambar justru kerencuan logika. Mendahului klaim Dewan Jenderal adalah rekayasa CIA, sebuah paragraf menyebutkan bahwa:

Sebelum meletus G30S, yakni setelah terdengar berita secara verbal bahwa Bung Karno telah menunjuk Letjen Ahmad Yani sebagai calon penggantinya, jika kesehatan Bung Karno yang mengidap pengakit ginjal terus menurun. Sejak itu mulai timbul di gejolak dan terdengar isu seolah-olah ada suatu gerakan yang disebut Dewan Jenderal yang akan melancarkan kudeta kepada Bung Karno. (Winardi, 2017)

Jika benar bahwa Dewan Jenderal adalah isu buatan CIA untuk menggulingkan Presiden Soekarno, publik mempertanyakan tujuan CIA tersebut. Hal ini disebabkan tidak ada penjelasan yang disebutkan dalam artikel tersebut yang dapat menjadi alasan yang mendesak bagi CIA untuk memancing munculnya G30S.

Pernyataan verbal Presiden Soekarno sebenarnya sudah cukup untuk memantik kekuatan komunis untuk melakukan sebuah gerakan. Sangat dapat diduga PKI tidak akan berdiam diri, karena Yani (yang digadang-gadang sebagai pengganti Soekarno) adalah seorang antikomunis. Kekuatan prokomunis tentu akan berkonsolidasi untuk lebih awal merebut kekuasaan, tidak menunggu sampai kekalahan datang mejemput. Mungkin saja artikel ini ingin menunjukkan bahwa dengan menyebar isu Dewan Jenderal, CIA dapat mempercepat upaya untuk memukul balik PKI. Namun tidak satupun argumentasi yang mendukung kategori itu. Dengan minimnya informasi yang tersaji dalam artikel di situs berita, tampak bahwa isu Dewan Jenderal tidak ada kaitannya dengan CIA. Oleh karena isu dewan ini sebenarnya lebih menguntungkan PKI karena mereka dapat menggunakannya untuk melakukan tindakan "preventif".

Keputusan media untuk tetap memunculkan kategori PKI sebagai dalang G30S pada dasarnya tidak memperkaya penafsiran atas peristiwa yang telah berusia lebih dari setengah abad ini. Dengan mengangkat topik Dewan Jenderal, jurnalis sebenarnya dapat mengintegrasikannya dengan beberapa skenario tentang G30S. Terlihat adanya upaya media untuk menggandengkannya dengan skenario ketelibatan CIA, namun itu gagal secara naratif. Elemen-elemen penyusunnya tidak mendukung. Jika lebih serius, isu Dewan Jenderal sangat mungkin dikaitkan oleh jurnalis dengan skenario yang melihat G30S sebagai masalah internal Angkatan Darat (AD). Sebagaimana yang diketahui, komposisi Dewan Jenderal pada dasarnya adalah para perwira tinggi di lingkup AD.

Isu Dewan Jenderal juga tidak dapat lepas dari Soekarno. Di mata sang Presiden, ini hal yang serius. Bisa jadi penilaian itu merupakan hasil dari kemampuan Subandrio untuk 
meyakinkannya. Yang pasti pada tanggal 6 Juni 1965 di Istana Tampak Siring (Bali), Soekarno menjadikan isu ini sebagai bagian dari diskusinya bersama beberapa tokoh antara lain Subandrio, Chairul Saleh, Leimena, Jusuf Muda Dalam, dan Brigjen Sjafiuddin. Dia menuduh ada beberapa jenderal di kalangan $\mathrm{AD}$ yang tidak loyal kepadanya (Fic, 2008: 106). Isu Dewan Jenderal dan rencana penangkapannya juga diketahui oleh Soeharto melalui pengakuan Kolonel Latief, salah seorang pemimpin G30S (Pour, 2010: 301). Kesemua latar informasi tesebut mampu memperkaya pengetahuan publik atas sejumlah versi skenario dari G30S. Tidak semuanya dilihat dari sudut pandang PKI.

Hal mendasar yang belum terjawab dalam liputan media berita daring adalah bagaimana Dewan Jenderal itu didefinisikan. Tiap pihak punya penafsiran masing-masing. PKI menyebut Dewan Jenderal dengan julukan "Kabir" (Kapitalis Birokrat). Secara ke dalam ini didefinisikan sebagai sekelompok petinggi AD yang selalu menentang setiap rencana PKI. Namun secara keluar, kapitalis birokrat adalah penggambaran buat orang yang mempunyai kedudukan di dalam lembaga pemerintah atau di dalam organisasi politik yang menyalahgunakan kekuasaan dan kedudukan untuk memperkaya golongan atau diri sendiri. Cakarabirawa menggambarkan Dewan Jenderal sebagai kapitalis birokrat menurut definisi PKI keluar dengan menambahkan bahwa mereka memiliki rencana untuk membunuh Presiden Soekarno setidaknya berencana melakukan kudeta. Soekarno sendiri menyebut Dewan Jenderal degan cara yang lebih moderat yaitu kelompok jenderal AD yang selalu menentang kebijakannya.

Di mata Achmad Yani sebagai Menteri/Panglima AD, tidak ada Dewan Jenderal sebagaimana yang dimaksud oleh Presiden Soekarno. Yang ada hanyalah Dewan Dewan Jabatan dan Kepangkatan Perwira Tinggi (disingkat Wanjakti). Brigjen Ahmad Soekendro mengakui keberadaan Dewan Jenderal. Namun sebagai kelompok yang aktif melakukan counter politik untuk menandingi dominasi PKI. Sementara CIA menyebut siapa saja jenderal yang bersahabat dengan mereka, itulah Dewan Jenderal yang dapat diandalkan untuk membendung pengaruh komunis di Indonesia. Semua kemungkinan interpretasi ini selalu terbuka untuk didiskusikan sebab Dokumen Gilchrist yang menjadi petunjuk isu ini pun tidak dengan spesifik menyebut nama Dewan Jenderal. Dokumen itu hanya memuat rangkaian kata "...our local army friends ..." (Fic, 2008: 370).

Konon Dokumen Gilchrist berasal dari sebuah telegram dari Duta Besar Inggris di Jakarta yang bernama Andrew Gilchrist yang ditujukan kepada Kantor Kementerian Luar Negeri Inggris. Telegram ini mengacu pada rencana gabungan intervensi militer AS-Inggris di Indonesia dengan menggandeng apa yang mereka sebut sebagai "our local army friends". Dokumen ini dikabarkan bocor 
dan sampai ke tangan Subandrio. Selain sebagai Wakil Perdana I, dia juga menjabat sebagai Kepala Badan Pusat Intelijen. Subandrio meyakini keaslian telegram diplomatik tersebut dan membawanya ke Soekarno. Menurut Dake (2005: 267), meski memperlihatkan kesan skeptis atas dokumen tersebut, Soekarno mempercayai Subandrio dan Sutarto (staf Badan Pusat Intelijen) yang menunjukkannya. Tidak adanya penjelasan latar dari Dewan Jenderal, menjadikan topik ini hanya sebentuk memori banal. Media cenderung mewariskan sesuatu ingatan yang dangkal padahal telah melewati masa setengah abad setelah peristiwa G30S itu terjadi.

\section{KESIMPULAN}

Penelitian ini menemukan bahwa artikel Dewan Jenderal belum tersaji dengan cara yang memenuhi standar rasionalitas narasi sebagaimana disyaratkan oleh Fisher. Elemen kohesifitas dan ketepatannya masih meragukan. Argumentasi yang digunakan belum cukup kuat untuk menegaskan keyakinan atas silogisme yang ditarik. Meski demikian, penggambaran Dewan Jenderal dan anggotanya dalam kategori patriot/pahlawan, terkonfirmasi dalam pembingkaian yang dilakukan situs berita utama Indonesia. Dalam konteks G30S, PKI tetap posisikan sebagai dalang. Media tidak memberikan versi lain yang dapat membuka wawasan publik untuk memahami lebih baik tragedi ini. Kecenderungan untuk menyajikan momen penculikan dan pembunuhan, menggiring pembingkaian lebih pada aspek dramatis (ketimbang latar politis yang lebih penting). Media tampak ingin menghadirkan Dewan Jenderal dan G30S sebagai sebuah isu dan peristiwa yang menonjolkan nilai human interest ketimbang nilai penting peristiwa tersebut dalam sejarah Indonesia.

Untuk penelitian lebih lanjut, khususnya terkait dengan kajian memori media, direkomendasikan melanjutkan pengungkapan pada tiga ranah. Pertama, di tingkat jurnalis sebagai pihak yang memproduksi pesan media. Beberapa asumsi yang dikemukakan dalam temuan penelitian ini dapat ditindaklanjuti. Kedua, berkaitan dengan pengungkapan artikel lain (di luar tiga situs berita utama di Indonesia). Pendekatan penelitian ini memilih situs utama untuk mengetahui kualitas substansi narasi yang banyak dikonsumsi oleh pembaca. Rekomendasi ditujukan kepada penelitian sejumlah artikel yang mungkin saja lebih lengkap dapat pada satu atau dua situs yang menyajikan artikel sejarah populer. Ketiga, bagi yang tertarik pada kajian reseptor, penting untuk mengkonfirmasi memori publik dengan apa yang disajikan oleh media. Boleh jadi publik memiliki cara penafsiran yang berbeda, mengoreksi, atau menerima begitu saja apa yang disajikan media.

\section{UCAPAN TERIMA KASIH}

Di bagian akhir, peneliti mengucapkan terima kasih kepada Prof. (Emeritus) Alwi Dahlan yang memperkenalkan kajian memori media. 
Di kelas beliau, peneliti menemukan ranah kajian media yang menanti untuk diungkap. Peneliti juga berterima kasih kepada Eduard Lukman M.A. yang banyak memberi wawasan seputar Peristiwa 1965, sejarah seolah mata air pengetahuan yang tidak kunjung kering untuk terus gali. Peneliti banyak mendapat tambahan pemahaman dari Dr. Eriyanto terkait perspektif penelitian teks media. Terima kasih yang juga tidak lupa peneliti haturkan kepada Ignatius Haryanto, mentor sekaligus teman diskusi media dan jurnalisme.

\section{DAFTAR PUSTAKA}

Airlanga, Mathew. 2018. Indonesia Digital Landscape 2018. Jakarta: GDP Venture.

Dake, Antonie C.A. 2005. Sukarno File, Berkas-Berkas Soekarno 19651967: Kronologi Suatu Keruntuhan. Jakarta: Aksara Karunia.

Eriyanto. 2011. Analisis Framing: Konstruksi, Ideologi, Dan Politik Meida. Yogyakarta: LKiS.

Fic, Victor M. 2008. Kudeta 1 Oktober 1965: Sebuah Studi Tentang Konspirasi. Jakarta: Yayasan Obor Indonesia.

Fisher, Walter R. 1987. Human Communication as Narration: Toward a Philosophy of Reason, Value, and Action. Columbia: University of South Carolina Press.

Fulton, Helen, Rosemary Huisman, Julian Murphet, and Anne Dunn. 2005. Narrative and Media. Cambridge: Cambridge University Press.
Griffin, Emory A. 2012. A First Look at Communication Theory. 8th ed. New York: McGraw-Hill.

Hadi, Kuncoro. 2017. Kronik '65:

Catatan Hari Per Hari Peristiwa G30S Sebelum Hingga Setelahnya (1963-1971). Yogyakarta: Media Pressindo.

McQuail, Denis. 2010. Mass

Communication Theory. 6th ed. London: Sage Publications.

Pour, Julius. 2010. Gerakan 30 September: Pelaku, Pahlawan, Dan Petualang. Jakarta: Penerbit Buku Kompas.

Soekarno. 1965. Subur, Subur, Suburlah PKI: Pidato Presiden Sukarno Pada Rapat Raksasa Ulangtahun Ke-45 PKI. Jakarta: Yayasan Pembaruan.

Sulistyo, Hermawan. 2011. Palu Arit Di

Ladang Tebu: Sejarah

Pembantaian Massal Yang

Terlupakan (Jombang-Kediri

1965-1966). Jakarta: Pensil-324.

Wanandi, Jusuf. 2014. Menyibak Tabir

Orde Baru: Memoar Politik

Indonesia 1965-1998. Jakarta:

Penerbit Buku Kompas.

\section{INTERNET}

Dariyanto, Erwin. 2017a. "Firasat Jelang Malam Jahanam (2): Pertanyaan Aneh Jenderal Prapto Sebelum Malam G30S/PKI.” Detik.com. September 29, 2017. https://news.detik.com/berita/d3663580/pertanyaan-anehjenderal-prapto-sebelum-malamg30spki.

-. 2017b. "Firasat Jelang Malam

Jahanam (4): Cerita Nisan

Pejuang Sejati Dan Burung Sriti Jelang G30S/PKI." Detik.com. September 29, 2017.

https://news.detik.com/berita/d- 
3664063/cerita-nisan-pejuangsejati-dan-burung-sriti-jelangg30spki. .2017c. "Firasat Jelang Malam Jahanam (5): G30S/PKI Dan 10 Buku Yang Tak Sempat Dibaca DI Pandjaitan." Detik.com. September 29, 2017. https://news.detik.com/berita/d3664329/g30spki-dan-10-bukuyang-tak-sempat-dibaca-dipandjaitan.

. 2017d. "Firasat Jelang Malam Jahanam: Perjamuan Terakhir Jenderal Ahmad Yani."

Detik.com. September 29, 2017. https://news.detik.com/berita/d3663349/perjamuan-terakhirjenderal-ahmad-yani.

Dariyanto, Erwin, and Samsudhuha

Wildansyah. 2017. "Firasat Jelang

Malam Jahanam (3): Jelang Malam G30S/PKI, MT Haryono

Suka Melamun Dan Jauhi Si Bungsu." Detik.com. September 29, 2017.

https://news.detik.com/berita/d3663858/jelang-malam-g30spkimt-haryono-suka-melamun-danjauhi-si-bungsu.

Prasetiyo, Rimawan. 2017. "Pengakuan

Eks Cakrabirawa Yang Menjemput Para Jenderal, Latif Dan Untung Lapor Ke Soeharto.” Tribunnews.com. Oktober 2017. http://bangka.tribunnews.com/201 7/10/04/pengakuan-ekscakrabirawa-yang-menjemputpara-jenderal-latif-dan-untunglapor-ke-soeharto?page=all.

Rimadi, Luqman. 2017. "Kisah Letjen S Parman, Korban G30S Yang Adik Tokoh PKI." Liputan6.com. September 29, 2017. http://news.liputan6.com/read/311 0730/kisah-letjen-s-parmankorban-g30s-yang-adik-tokoh-pki.
Surono, Agus. 2017. “Tak Disangka! Ternyata Ada 8 Jenderal Sempat Akan Dibantai PKI, 1 Sosok Ini Lolos, Siapa?” Tribunnews.com. Oktober 2017. http://style.tribunnews.com/2017/ 10/02/tak-disangka-ternyata-ada8-jenderal-sempat-akan-dibantaipki-1-sosok-ini-lolossiapa?page $=$ all.

Wardayati, K. Tatik. 2017. "Cerita Kekejaman G30S/PKI, Mereka Yang Lolos Dari Lubang Buaya." Tribunnews.com. September 20, 2017. http://m.tribunnews.com/nasional/ 2017/09/20/cerita-kekejamang30spki-mereka-yang-lolos-darilubang-buaya? page $=$ all.

Winardi, Agustinus. 2017. "Militer AS Sudah Siap Menginvasi Indonesia Jika Upaya CIA Mendorong G30S Urung Terjadi." Tribunnews.com. September 29, 2017. http://bangka.tribunnews.com/201 7/09/29/militer-as-sudah-siapmenginvasi-indonesia-jika-upayacia-mendorong-g30s-urungterjadi?page=all. 